\title{
SELECTION AND SURVIVAL IN LOLIUM PERENNE
}

\author{
M. D. HAYWARD \\ Welsh Plont Breeding Stotion, Aberystwyth
}

Received 15.ix.69

\section{INTRODUCTION}

ThE mature grass sward is composed of individuals whose common phenotypic expression is a result of the ability of the genotype to survive the intense competitive conditions and the ever changing environmental factors which operate upon the pasture.

Studies on the establishment of ryegrass pastures have revealed that the number of plants surviving to maturity is only about 10 per cent. of those which initially germinate. Competition and selective elimination during this phase rapidly alter the phenotype of the population depending primarily upon the system of management imposed (Charles, 1961, 1966). A knowledge of the changes in this phenotypic composition of a cultivar, and of the underlying genetic determination is of direct practical importance in the furtherance of the aims of the herbage breeder.

The present experiment seeks to examine the variation exhibited by the survivors of a sown cultivar of perennial ryegrass (Lolium perenne L.) and to assess the mode of gene action involved and hence the manner in which selection may have operated on the pasture.

\section{Materials and methods}

The material consisted of two groups of Lolium perenne plants derived from the cultivar S.24, kindly supplied by Dr A. H. Charles. The original group consisted of a sample of ten taken from individual spaced plants of the variety grown in the experimental field at the Welsh Plant Breeding Station, Aberystwyth. The survivor group of ten plants were also taken from the spaced plant nursery, but they themselves originated from clonal material collected from a pasture in the West Midlands which had been sown down to the same stock of seed and subjected to intense sheep and cattle grazing for some two years prior to sampling (Centre V of Charles, 1966). The two groups of plants were thus of the same generation but differed in actual age; the original group being only two years old at the commencement of the experiment while the survivor group was approximately four years old.

The experiment consisted of two parts run concurrently, the first being a phenotypic analysis of the vegetative material. Each plant was split into 20 clonal parts or ramets; ten ramets being allocated to each of two blocks of a spaced plant $(2 \mathrm{ft} . \times 2 \mathrm{ft}$.) randomised block experiment. The second part is a genetic assessment by means of a progeny test of the variation exhibited by these two groups of plants. The two groups were crossed together in the form of a North Carolina Model II mating design (Comstock and Robinson, 1952), i.e., each plant of the original group is mated to each 
of the survivor group. The technique of automatic cross pollination without emasculation was used, units being separated after the completion of anthesis to maintain reciprocal crosses distinct. Check selfings were also carried out, the percentage seed set being virtually nil throughout. One of the survivor plants proved to be almost sterile with very little seed set, which necessitated its omission and reduction of the design to a $9 \times 9$ design.

Seed of each of the progeny families was sown in the glasshouse in 1967 and 20 seedlings were later transplanted to the field into the same experimental layout as the clonally propagated parent material. Data were collected on four field characters : production from an establishment cut in the autumn of the seeding year and from a conservation cut at the hay stage of the first harvest year, both recorded as yield in grammes of fresh material, date of inflorescence emergence as the number of days after 1st May 1968 when three inflorescences had appeared and, finally, the number of inflorescences produced in the aftermath.

\section{Results}

(i) Clonal analysis

The mean phenotype of the four characters of the clonally propagated parental plant data of both groups is shown in table 1, with the summarised

TABLE 1

Mean phenotype of the clonally propagated parent material

\begin{tabular}{|c|c|c|c|c|}
\hline & $\begin{array}{l}\text { Establishment } \\
\text { cut }(g)\end{array}$ & Hay cut $(g)$ & $\begin{array}{c}\text { Date of inflorescence } \\
\text { emergence } \\
\text { (days after 1st May 1968) }\end{array}$ & $\begin{array}{c}\text { Number of aftermath } \\
\text { inflorescences }\end{array}$ \\
\hline Original & $\begin{array}{r}324 \\
\pm 26\end{array}$ & $\begin{array}{r}455 \\
\pm 44\end{array}$ & $\begin{array}{r}33 \cdot 2 \\
\pm 1 \cdot 2\end{array}$ & $\begin{array}{r}22 \cdot 4 \\
\pm 4 \cdot 1\end{array}$ \\
\hline Survivors & $\begin{array}{r}203 \\
\pm 38\end{array}$ & $\begin{array}{r}420 \\
\pm 80\end{array}$ & $\begin{array}{r}37 \cdot 0 \\
\pm 4 \cdot 1\end{array}$ & $\begin{array}{r}23.6 \\
\pm 4.8\end{array}$ \\
\hline
\end{tabular}

results of an analysis of variance in table 2. The overall differences in the mean of the two groups was assessed by testing the between group mean square against the variation betwen clones within both groups. This latter item was itself compared with the between ramet item within both sets of clones. The between clone item was split down to its two group components, i.e. originals and survivors, each being tested against their own residual variation.

Overall differences between the two groups occurred only for production during the establishment phase. In contrast, there were highly significant differences between the clonal plants of both groups for all four characters, thus suggesting the existence of genetic variation between plants (see table 2). In all instances the variation between survivor clones was greater than between the members of the original group, however, it was significant $(P=0.01)$ only for the date of inflorescence emergence.

An examination of the residual variation exhibited by the clonal ramets reveals that, in contrast to the situation for the variance between clones, here the variation for each character is significantly greater for the original group than for the survivors (see table 2). 


\section{(ii) Progeny test}

The nature of the genetic control of the variation between the clonal plants, as shown in the previous section, was assessed by analysis of the Model II crossing scheme. The analysis of variance consisted of two parts, that based on $(a)$ reciprocal sums, and $(b)$ on reciprocal differences of the progeny family means. From the reciprocal sums, the main effects, original and survivor, reveal the existence of any additive genetic variation present in either group. From the reciprocal differences part of the analysis the action of average maternal or plasmon effects is detected. The interaction of the main effects $(O \times S)$ confirms from the reciprocal sums the presence of nonadditive variation, i.e. dominance or epistasis at the nuclear genetic level,

TABle 2

Analysis of clonally propagated parent material

\begin{tabular}{|c|c|c|c|c|c|}
\hline Item & d.f. & $\begin{array}{c}\text { Establishment } \\
\text { cut }\end{array}$ & $\begin{array}{c}\text { Mean squares } \\
\text { Hay cut }\end{array}$ & $\begin{array}{c}\text { Inflorescence } \\
\text { emergence }\end{array}$ & $\begin{array}{l}\text { Number of } \\
\text { inflorescences }\end{array}$ \\
\hline Between groups & 1 & $1,236,694^{* *}$ & 71,706 & 1,335 & 295 \\
\hline Between clones & 16 & $174,260 * * *$ & $719,958 * * *$ & $1,066^{* * *}$ & $2,916 * * *$ \\
\hline Within Original & 8 & $83,288 * * *$ & $364,629 * * *$ & $\begin{array}{l}228 * * * \\
(* * *)+\end{array}$ & $2,704 * * *$ \\
\hline Within Survivor & 8 & $265,233^{* * *}$ & $1,075,287 * * *$ & $1,905^{* * *}$ & $3,128 * * *$ \\
\hline $\begin{array}{l}\text { Between ramets } \\
\text { within clones }\end{array}$ & 333 & 8,268 & 25,898 & 11 & 242 \\
\hline $\begin{array}{l}\text { Within Original } \\
\text { Within Survivor }\end{array}$ & $\begin{array}{l}170 \\
163\end{array}$ & $\begin{array}{l}14,290 \\
2,966^{(* * *)}\end{array}$ & $\left.\begin{array}{l}34,103 \\
17,342\end{array}{ }^{(* *}\right)_{+}^{*}$ & $7^{(*) *}$ & ${ }_{181}^{303}\left({ }^{*}\right)_{+}^{*}$ \\
\hline
\end{tabular}

whilst from the differences it indicates the occurrence of maternal plasmon or nuclear/plasmon interactions. The main effects were tested against the first order interaction which was itself initially compared with the error. The latter represents the residual variation of the main effects and interaction over replicates. The reduced degrees of freedom appropriate to both errors were due to the absence of some families and/or reciprocals as a consequence of low seed setting on crossing or poor establishment in the field.

The mean squares of the analysis of variance are shown in table 3. In contrast to the results from the clonal analysis there would appear to be little evidence of heritable variation present, as only the main effect mean square for the date of inflorescence emergence is significant both for reciprocal sums and differences. There would appear to be variation in the genetic control of the number of heads produced in the aftermath, but only for the original group not for the surviving population. For this character, however, there is no evidence of any variation of the average maternal form (see table 3).

The interaction item $(O \times S)$ is significant for the reciprocal sums only for the timing of inflorescence emergence and the number of inflorescences 
produced in the aftermath, but for the reciprocal differences it is significant for these two characters and also for the production at the conservation cut. These results would suggest that the plants within the two groups are differentiated at the non-additive genetic level for the reproductive characters, and at the plasmon or nuclear/plasmon level for both these and the additional productivity character.

Table 3

Analysis of progeny family means

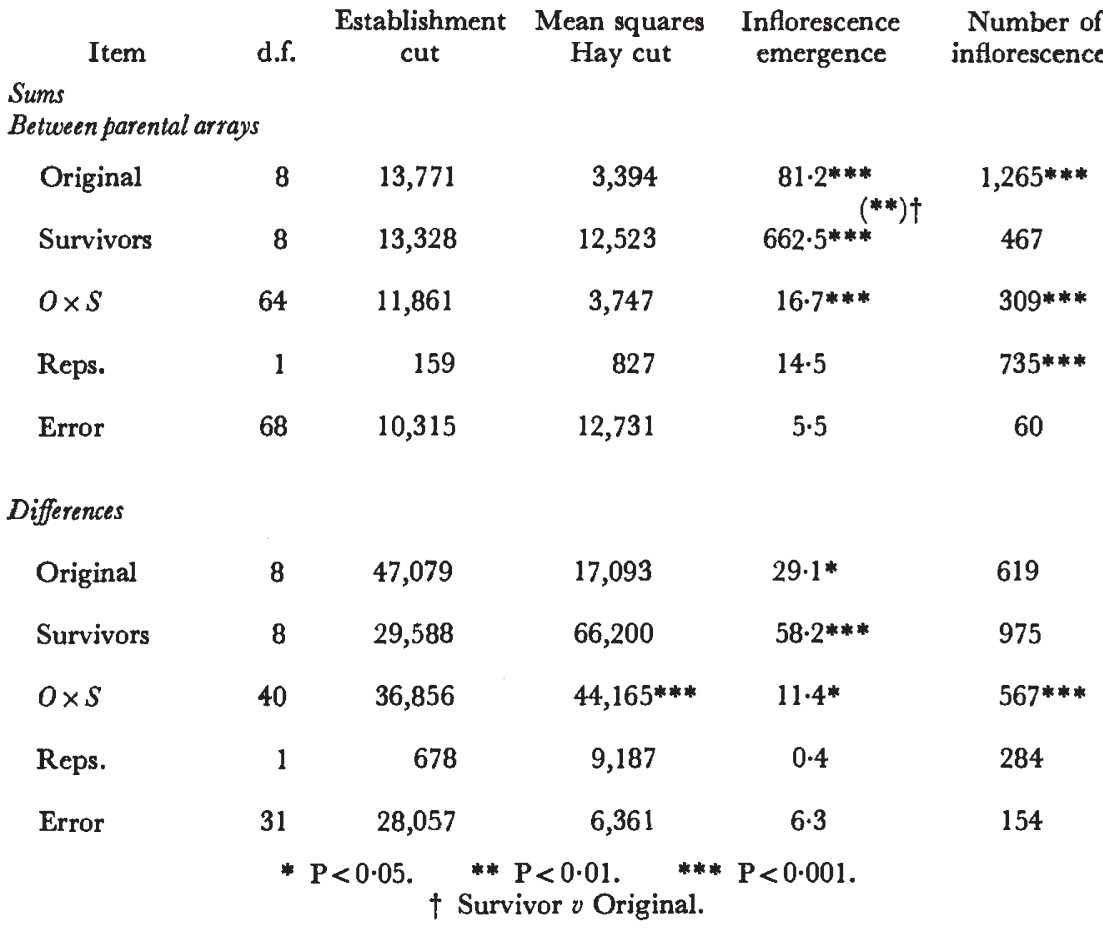

\section{Discussion}

The results presented here pose a series of problems as to the manner in which selection has operated during the establishment of the sward and in the control and maintenance of variability within the population of surviving individuals.

Considering first the results from the clonal analysis, it would appear that there is considerable variation between individual clones within both groups, variation which, according to the mode of analysis (Burton and de Vane, 1953) is generally held to be genetic in origin. The magnitude of the variation differs, however, between the two groups, being greater for the surviving group throughout. This would suggest that as the means of the two groups do not differ, except for the production at the establishment cut, the variance of the survivors has increased beyond the range of the original population. This is particularly true for the timing of inflorescence emergence, the survivors showing a range of 34 days compared with 12 days for the original population. This is at variance with previous studies of sown popu. 
lations (Charles, 1966) where survivors generally exhibit a very restricted range for this character. The only difference in the means of the two groups, for the production at the establishment cut, reflects the decreased productivity of the survivors due possibly to physiological age differences between them. This latter point is in contrast to the results of Davies and Troughton (1968) who found in a comparable experiment that surviving plants outyielded the original.

The higher residual variation of ramets within original clones compared with those within survivors may be a further example of the situation described by Breese et al. (1965) in their clonal selection experiments with perennial ryegrass. Here a response to selection could be elicited in young clones derived from seedlings but not from old clones collected from permanent pastures. This was interpreted as somatic selection having already operated in the sward for a stable plasmatype. A similar situation may hold in the present instance, the survivor clones having achieved a more stable plasmon than the younger original clones. Alternatively, of course, the differential action of virus in a symptomless form cannot be completely ruled out.

A further insight into the control of this phenotypic variation is provided by the progeny test of the second part of the experiment. The differences between the members of the two groups for the production characters, as shown by the clonal analysis, do not appear to be under either nuclear genetic or plasmon control; a situation which also applies for the survivor group in the number of inflorescences produced in the aftermath. The significant interaction item of the reciprocal sums for the inflorescence production and for the reciprocal differences for both this character and the harvest hay cut may suggest that possible directional or disruptive selection in the sward had occurred. Plasmon differentiation may well have arisen during the numerous tiller generations which the material, especially the survivor plants, had gone through. However, the possibility that such interactions, both nuclear and plasmon, are characteristic of the genetic organisation of the original population cannot be ruled out. The mating design adopted does not allow a distinction to be made between these two possible sources of variation, as the necessary crosses within each group are not included. For these characters, therefore, the gross variation does not appear to be controlled by the nuclear or plasmon genotype at the simple additive level, there is however the possible action of specific nuclear or nuclear/plasmon effects.

Turning to the final character, timing of inflorescence emergence, the situation contrasts markedly with that of the previous characters. Here variation is present in both groups for nuclear genetic and plasmon control at both the additive and interactive levels. This would indicate that disruptive selection has occurred on the original population to such an extent that the genotype of the survivors markedly differs from the original, so much so, that the variance of the survivors is significantly greater than that of the originals. At this stage of experimentation it is only possible to speculate as to the mechanism which has given rise to this apparent increase in heritable variation. It is not simple plasmon control, as the reciprocal sum mean squares are still highly significant when tested against their corresponding reciprocal differences (see table 2). This suggests that there has been some apparent generation of genetic variance.

It may well be that the greater variation of the survivor genotypes has 
arisen as a result, of the action of a "frequency dependent " form of selection operating on the pasture. Plants of differing phenotype may survive as they show less intense competition with one another, i.e. they make different demands upon the environment, compared with plants of similar phenotype. Alternatively, since both groups are but a small sample of a larger population, the possibility cannot be ruled out that this effect is due purely to sampling. One further point of caution: although adequate safeguards were taken at the time of sowing the experimental sward (Charles, personal communication) invasion by alien genotypes may have occurred. It is quite apparent that whatever process is involved it is of considerable importance in the study of sward dynamics and requires further investigation.

From this first experiment, therefore, we have to conclude that the very large phenotypic differences for the production characters which were apparent from the clonal analysis are not generally transmitted by nucleus or plasmon to the progeny. This " plasticity", arising in the establishment phases of a sward, is however of a form which is maintained on transference of the plant material to an alternative environment and during the continual vegetative reproduction which occurs in the growth of the plant. This is in contrast to the situation in Trifolium described by Bradshaw (1965) where the plasticity of petiole length is reversible, the response varying according to the conditions under which leaf production occurs. In contrast, the characters associated with sexual reproduction display an apparent increase in heritable variation after a period of growth in the sward. These results may appear to be in conflict with our previous thesis (Hayward and Breese, 1968) as to the importance of asexual productivity characters as a source of potential variation in the persistent ryegrasses. In the present instance, however, we are dealing with a bred variety which is characteristically maintained by seed, and hence variability, both nuclear and plasmon, for the processes involved in sexual reproduction may well be of adaptive significance.

\section{Summary}

1. A phenotypic examination of plants collected from a sown pasture of Lolium perenne reveals that for most of the characters examined, production at two cuts and inflorescence development, there is an increase of variability of the survivor clones compared with the original population.

2. There is a corresponding decrease in the intraclonal variation of the survivors.

3. An assessment of the genetic control of this variation by means of a partial diallel cross, indicates that for the production characters there is no genetic basis for the observable phenotypic variation.

4. For the inflorescence characters, timing of emergence and aftermath flowering, there is considerable genetic variation present, with an apparent increase of heritable variance for the survivors. This variance may be both nuclear genetic and plasmon in origin.

5. These results are discussed in relation to the selective force known to operate on a pasture.

Acknowledgments.-I wish to thank Professor P. T. Thomas, C.B.E., Director, Welsh Plant Breeding Station, and Dr E. L. Breese for their interest and guidance in this work, Dr A. H. Charles for supplying the material, and Dr J. Gale, Department of Genetics, University of Birmingham, for helpful discussion on the method of statistical analysis. 


\section{REFERENCES}

BRADSHAW, A. 1965. Evalutionary significance of phenotypic plasticity in plants. Adv. Genet., 13, 115-155.

BREESE, E. L., HAYWARD, M. D., AND THOMAS, A. C. 1965. Somatic selection in perennial ryegrass. Heredity, Lond., 20, 367-379.

BURTON, G. W., AND DE VANE, E. H. 1953. Estimating heritability in tall fescue (Festuca arundinacea) from replicated clonal material. Agron. 7., 45, 478-481.

Chardes, A. H. 1961. Differential survival of cultivars of Lolium, Dactylis and Phleum. 7. Br. Grassld Soc., 16, 69-75.

CHARLES, A. H. 1966. Variation in grass and clover population in response to agronomic selection pressures. Proc. X Int. Grassld Congr., Helsinki, 625-629.

COMSTOGK, R. E., AND ROBINSON, H. F. 1952. Estimation of average dominance of genes. In: Heterosis, pp. 494-516. Ames Iowa State Coll. Press.

DAVIEs, A. G., AND Troughton, A. 1968. Intra-varietal selection in swards. Rep. Welsh Pl. Breed. Stn for 1967, 62-63.

HAYWARD, M. D., AND BREESE, E. L. 1968. Genetic organisation of natural populations of Lolium perenne. III. Productivity. Heredity, Lond., 23, 357-368. 